\title{
Seeker Optimization Algorithm based Load Frequency Control of Interconnected Power Systems
}

\author{
S.Ramesh Kumar \\ Asst. Professor, Dept of Electrical Engg., \\ Annamalai University, Annamalai nagar, \\ Chidambaram, Tamilnadu, India-608002.
}

\author{
S.Ganapathy \\ Professor, Dept of Electrical Engg., \\ Annamalai University, Annamalai nagar, \\ Chidambaram, Tamilnadu, India-608002.
}

\begin{abstract}
In this paper, a Seeker Optimization Algorithm (SOA) based optimal proportional-plus-integral (PI) controller is designed for Load Frequency Control (LFC) of two area interconnected thermal power systems. Swarm intelligence algorithms have been successfully applied to solve optimization problems, Seeker optimization algorithm is one of the latest members of that class. Seeker optimization algorithm (SOA) is based on simulating the act of human searching, which has been shown to be a promising candidate among search algorithms for function optimization. The effectiveness of the proposed scheme is confirmed via extensive study using MATLAB/SIMULINK software. Simulation results are carried out by introducing $1 \%$ load disturbance in any one area of an interconnected power system. Comparison of performance responses of conventional Proportional-Integral (PI) controller with Proportional-Integral controller using Seeker Optimization Algorithm show that the Seeker Optimization Algorithm tuned controller has better dynamic response in the presence of system disturbances.
\end{abstract}

\section{Keywords}

Interconnected Power Systems, Load Frequency Control, Seeker Optimization Algorithm.

\section{INTRODUCTION}

Load Frequency Control is a very important issue in power system operation and control for supplying sufficient and reliable electric power with good quality. For large power systems with interconnected areas, Load Frequency Control (LFC) is vital to keep the system frequency and inter-area tieline power flow as close to the scheduled values as possible. The mechanical power input to the generators is used to control the frequency of output electrical power and the power exchange between the areas as scheduled. The objective of LFC of a power system is to maintain the frequency of each area and tie-line power flow (interconnected system) within specified tolerance by adjusting the new outputs of LFC [1]. In an interconnected power system, the balance of real power is provided by the amount of synchronous generators connected to the system. If the amount of generated power is less than the demand, the speed and frequency of the generator decreases, and vice versa. The frequency deviation is brought back to desired level by the control of turbines which in turn controls the generators. For this control purpose, the PI controller is used. By tuning the controller gains, the steady state error of the system is minimized, bringing the power system back to its normal mode of operation [2].

Due to the complex nature of modern interconnected power systems such as non-linear characteristics of loads connected to the power systems and variable operating conditions, the conventional methods for tuning of PI controller may be unsuitable. Many different control strategies have been suggested in literature based on intelligent/soft computing techniques [3]. Seeker Optimization Algorithm is based on human understanding and searching capability for finding an optimum solution. In the SOA, optimum solution is regarded as one which is searched out by a seeker population. The underlying concept of the Seeker Optimization Algorithm is very easy to model and relatively easier than other optimization techniques. In this study, Seeker Optimization algorithm is used to optimize the parameters of optimal PI controller gains.

\section{CONTROL CONFIGURATION}

The system investigated for Load Frequency Control in this study is a two area interconnected power system with two units in each area, one with reheat turbine type thermal unit and other non-reheat thermal unit. The generalized model of two area interconnected power system is shown in Fig.1. Standard notations for LFC have been used and data for the system is taken from [4].

The dynamic behavior of the LFC system is described by the state space equation:

$\dot{\mathrm{X}}=\mathrm{AX}+\mathrm{BU}+\Gamma \mathrm{D}$

Where $\mathbf{X}, \mathbf{U}$ and $\mathbf{D}$ are the state, control and disturbance vectors and $\mathbf{A}, \mathbf{B}$ and $\Gamma$ are respectively system state matrix, control input matrix and disturbance input matrix of appropriate dimension.

$\mathrm{X}=\left[\begin{array}{ccccccc}\Delta \mathrm{F}_{1} & \Delta \mathrm{P}_{\mathrm{g} 11} & \Delta \mathrm{X}_{\mathrm{e} 11} & \Delta \mathrm{P}_{\mathrm{g} 12} & \Delta \mathrm{P}_{\mathrm{g} 12}^{\prime} & \Delta \mathrm{X}_{\mathrm{e} 12} & \Delta \mathrm{P}_{\mathrm{e} 1} \\ \Delta \mathrm{F}_{2} & \Delta \mathrm{P}_{\mathrm{g} 21} & \Delta \mathrm{X}_{\mathrm{e} 21} & \Delta \mathrm{P}_{\mathrm{g} 22} & \Delta \mathrm{P}_{\mathrm{g} 22}^{\prime} & \Delta \mathrm{X}_{\mathrm{e} 22}\end{array}\right]^{\mathrm{T}}$

$\mathrm{U}=\left[\begin{array}{ll}\Delta \mathrm{P}_{\mathrm{c} 1} & \Delta \mathrm{P}_{\mathrm{c} 2}\end{array}\right]^{\mathrm{T}}$

$\mathrm{D}=\left[\begin{array}{ll}\Delta \mathrm{P}_{\mathrm{d} 1} & \Delta \mathrm{P}_{\mathrm{d} 2}\end{array}\right]^{\mathrm{T}}$

The system matrices $\mathbf{A}, \mathbf{B}$ and $\Gamma$ can be obtained with the structure of the state, control and disturbance vectors and the transfer function block diagram representation of Fig.1. 


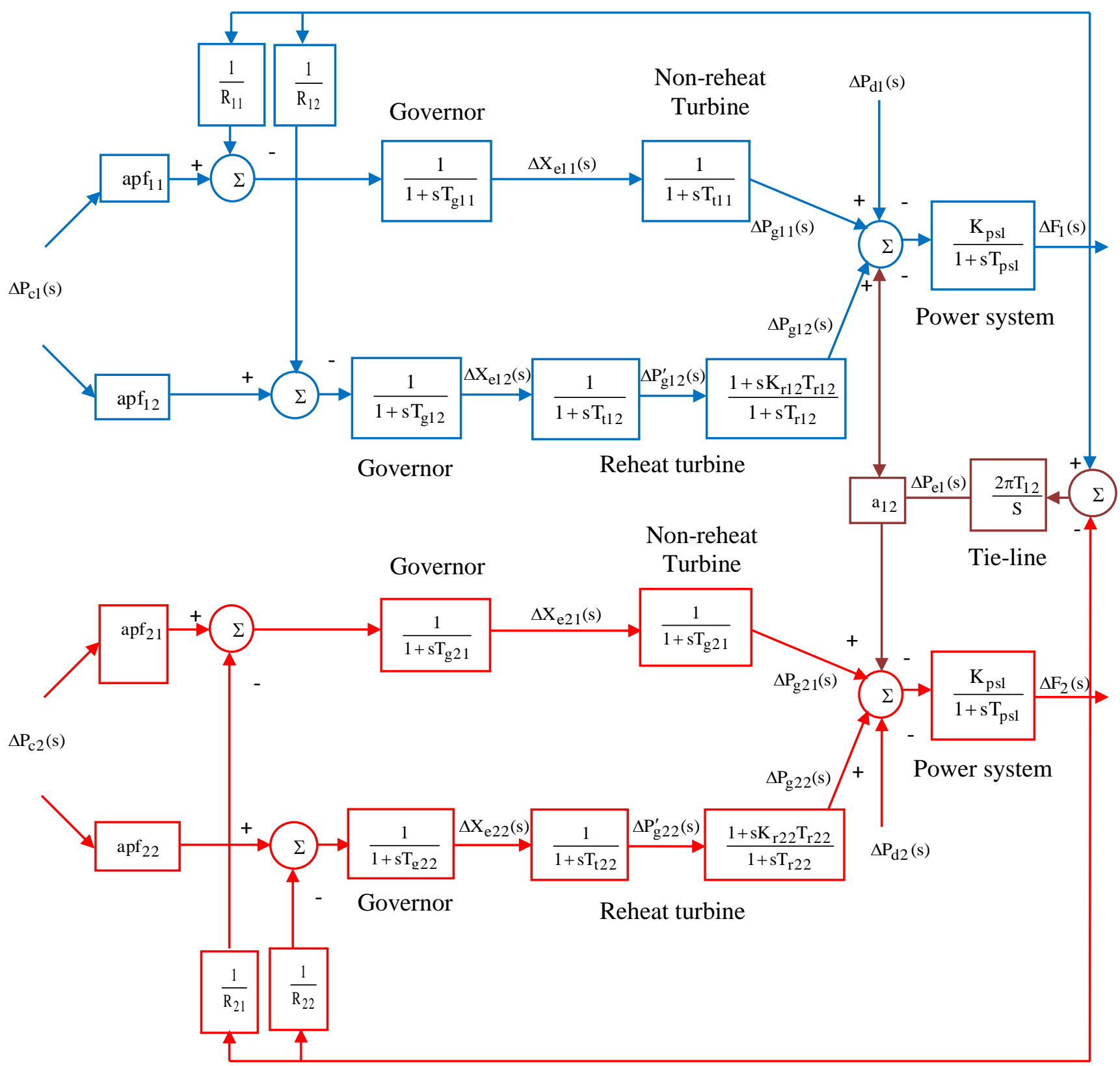

Fig.1. Block diagram representation of two area interconnected power system

The corresponding co-efficient matrices are obtained using the nominal system parameter values of the system. A step load disturbance of $1 \%$ has been considered as a disturbance in the system. For the frequency and tie-line power deviations to be zero at steady state, the Area Control Error (ACE) should be zero. To meet the above design requirement, the ACE is defined as:

$$
\mathrm{ACE}_{\mathrm{i}}=\Delta \mathrm{P}_{\text {tiei }}+\beta \Delta \mathrm{F}_{\mathrm{i}}
$$

where ' $i$ ' represents the control area and $\beta_{i}$ is the frequency bias constant. The objective is to obtain the optimum value of the controller parameters which minimize the performance index J [6]:

$$
J=\int_{0}^{t}\left(\Delta F_{1}^{2}+\Delta P_{\text {tiel }}^{2}\right) d t
$$

A new nature inspired metaheuristic search algorithm called as Seeker Optimization algorithm is used for the optimal designing of PI controller for LFC in two area interconnected power system to damp the power system oscillations. To simplify the analysis, the two interconnected areas are considered identical. The optimal parameter values are such that $\mathrm{K}_{\mathrm{p} 1}=\mathrm{K}_{\mathrm{p} 2}=\mathrm{K}_{\mathrm{p}}$ and $\mathrm{K}_{\mathrm{i} 1}=\mathrm{K}_{\mathrm{i} 2}=\mathrm{K}_{\mathrm{i}}$.

\section{SEEKER OPTIMIZATION}

\section{ALGORITHM}

Seeker optimization algorithm (SOA) is a novel search algorithm for optimization problems, based on simulating the act of human searching. The Seeker optimization algorithm (SOA) has better global search ability and faster convergence speed, hence suits well for solving power system optimization problems. Seeker optimization algorithm (SOA) models the behavior of human search population based on their memory, experience, uncertainty reasoning and communication with 
each other [5]. The individual of the population is called seeker or searcher, the total population is equally categorized into three subpopulations according to the indexes of the seekers. Seekers in the same subpopulation constitute a neighborhood which represents the social component for the social sharing of information. Seeker $i$ has the following attributes: the current position $\mathrm{x}_{\mathrm{i}}=\left(\mathrm{x}_{\mathrm{i} 1} ; \mathrm{x}_{\mathrm{i} 2} ;: \ldots ; \mathrm{x}_{\mathrm{iD}}\right)$, the dimension of the problem $\mathrm{D}$, the iteration number $\mathrm{t}$, the personal best position so far $\mathrm{p}_{\text {best }}$ and the neighborhood best position so far $\mathrm{g}_{\text {best }}$. The algorithm uses search direction and step length to update the positions of seekers. Seeker's egoistic behavior, altruistic behavior and pro-activeness behavior are used to determine the search direction, while uncertainty reasoning behavior is used to determine step length. Search direction $\alpha_{i j}$ and step length $\mathrm{d}_{\mathrm{ij}}$ are separately computed for each individual $i$ on each dimension $j$ at each iteration $\mathrm{t}$, where $\alpha \mathrm{ij} \geq 0$ and $\mathrm{d}_{\mathrm{ij}} \in\{-1 ; 0 ; 1\}$. During each iteration, the position of each seeker is updated by:

$$
X_{i j}(t+1)=X_{i j}(t)+\alpha_{i j}(t) \cdot d_{i j}
$$

where $\mathrm{i}=1,2, \ldots, \mathrm{SN} ; \mathrm{j}=1,2, \ldots, \mathrm{D}$ (SN is the number of seekers). Also, at each iteration, the current positions of the worst two individuals of each subpopulation are replaced with the best ones in each of the other two subpopulations, which is called inter-subpopulation learning [5].

The pseudo-code for the SOA is [5]:

$\mathrm{t}=0$;

Generate SN positions uniformly and randomly in the search space;

Evaluate all the seekers and save the historical best position;

Repeat

Compute search direction and step length for each seeker;

Update each seeker's position using Eq. (7);

Evaluate all the seekers and save the historical best position;

Implement the inter-subpopulation learning operation;

$\mathrm{t}=\mathrm{t}+1$;

until $\mathrm{t}=\mathrm{T}_{\max }$.

\section{OPTIMAL TUNING OF PI CONTROLLER PARAMETERS}

The optimal PI values for the interconnected power system are tuned by using conventional method and also by using the seeker optimization algorithm and the results are tabulated below. In the conventional controller design, the integral square error (ISE) criterion of cost function is used to find the optimum controller gains. To employ ISE criterion, the performance index or cost function $\mathbf{J}$ is evaluated for various values of the PI gains. The cost function of area $\mathrm{i}, \mathrm{J}_{\mathrm{i}}$ is obtained by simulating the closed loop system for various values of $\mathrm{K}_{\mathrm{p}}$, keeping $\mathrm{K}_{\mathrm{i}}=0$ throughout. The cost curve is drawn between various values of gain $K_{p}$ and performance index $\mathrm{J}_{\mathrm{i}}$ as shown in fig.2. The value of gain corresponding to the lowest point on the curve or minimum $\mathrm{J}_{\mathrm{i}}$ is taken as the optimum controller gain value $\mathrm{K}_{\mathrm{p}}$ (optimum). Following the procedure, the PI controller is designed by simulating the closed loop system for various values of $\mathrm{K}_{\mathrm{i}}$ while keeping $\mathrm{K}_{\mathrm{p}}=\mathrm{K}_{\mathrm{p}}$ (optimum). The optimum $\mathrm{K}_{\mathrm{i}}$, corresponding to minimum $\mathrm{J}_{\mathrm{i}}$, is obtained from the cost curve of fig.3.
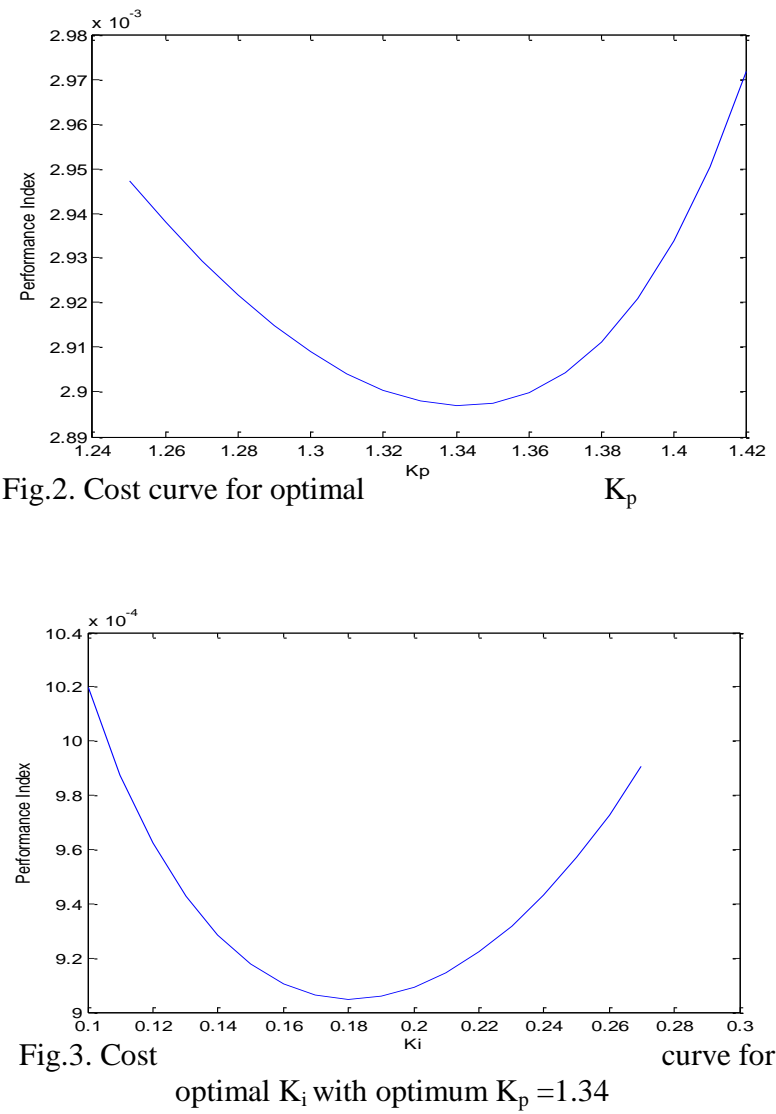

The application of SOA algorithm for optimum PI tuning involves repetitively performing the following steps.

1. The calculation of objective function (performance index or cost function) for each seeker in the current population. To do this, the system must be simulated to obtain the value of the objective function.

2. The seeker optimization algorithm then updates the position $\left(\mathrm{K}_{\mathrm{p}}\right.$ and $\left.\mathrm{K}_{\mathrm{i}}\right)$ of seekers based on search direction and step size.

These two steps are repeated from population to populationof seekers until a stopping criterion (maximum number of iterations) terminates the search producing the optimum gains. For this seeker optimization problem, the following parameters, dimension of the problem $\mathrm{D}=2$, number of iterations $\mathrm{t}=30$, number of seekers $\mathrm{SN}=36$ are used.

\section{SIMULATION RESULTS AND OBSERVATIONS}

The tuning of PI controller using seeker optimization algorithm is implemented in the two area interconnected thermal power system. The system is simulated with $0.01 \mathrm{p} . u$ MW step load change in area 1 and the corresponding frequency deviations and tie-line power deviations are plotted with respect to time. From the responses shown in figs. $4-5$, it is observed that the transient performance is improved significantly with quick settling time. The gain values and cost function values of the controllers are given in table 1.It is observed from table 1 that the cost function value of the controller tuned using seeker optimization algorithm is drastically reduced when compared to that of the controller tuned based on conventional approach. 
Table 1. Optimum controller values and cost function values

\begin{tabular}{|c|c|c|}
\hline $\begin{array}{c}\text { Type of proportional } \\
\text { plus integral } \\
\text { controller }\end{array}$ & $\begin{array}{c}\text { Feedback } \\
\text { Gains }\end{array}$ & $\begin{array}{c}\text { Cost } \\
\text { function } \\
\text { value }\end{array}$ \\
\hline $\begin{array}{c}\text { Controller tuned using } \\
\text { conventional method }\end{array}$ & $\begin{array}{c}\mathrm{K}_{\mathrm{p}}=1.34 \\
\mathrm{~K}_{\mathrm{i}}=0.18\end{array}$ & 0.5903 \\
\hline $\begin{array}{c}\text { Controller tuned using } \\
\text { SOA }\end{array}$ & $\begin{array}{c}\mathrm{K}_{\mathrm{p}}=0.3771 \\
\mathrm{~K}_{\mathrm{i}}=0.9250\end{array}$ & 0.3222 \\
\hline
\end{tabular}

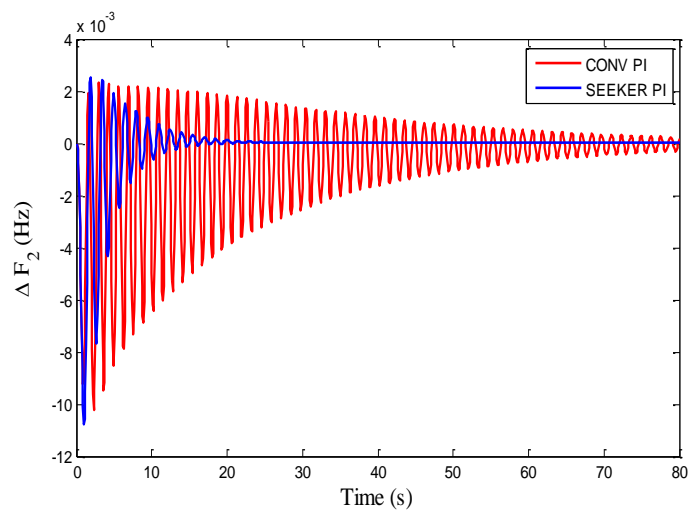

Fig.4. change of frequency in area-1

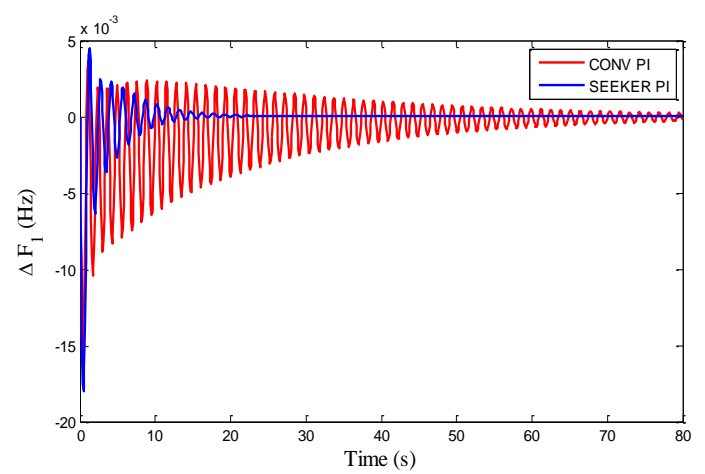

Fig.5. change of frequency in area-2

Fig.6. change of tie-line power

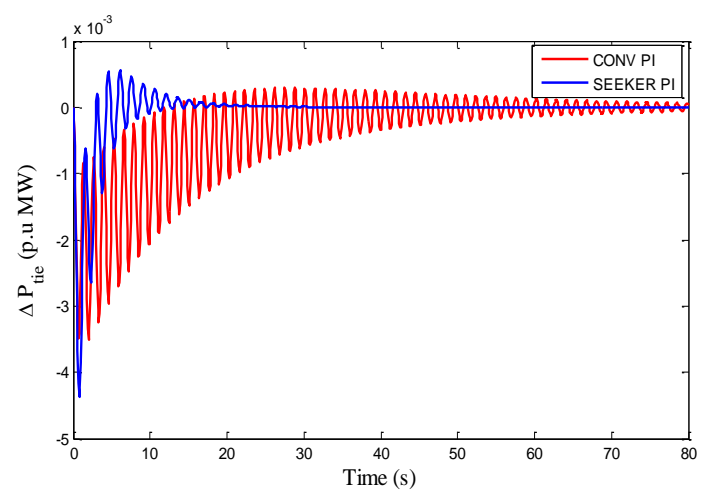

\section{CONCLUSION}

This study has presented an application of Seeker Optimization Algorithm (SOA) to determine the optimal parameters for the proposed two area interconnected power system. Seeker optimization algorithm has been used to obtain the optimal PI controller values. The proposed controller design has been successfully applied to an interconnected two-area thermal power system. Simulation studies have been carried out using MATLAB platform to study the transient behavior of the frequency of each area and tie line power deviations due to load perturbation in one of the areas. Simulation results reveal that the controller tuned using seeker optimization algorithm is very effective in suppressing the frequency and tie-line power oscillations.

\section{REFERENCES}

[1] N.Jaleeli, D.N.Ewart and L.H.Fink, "Understanding Automatic Generation Control",IEEE Transactions on Power System, vol. 7, no. 3, pp.1106-1122, Aug 2008.

[2] O.L.Elgerd and C.E.Fosha, "Optimal megawatt frequency control of multi-area electrical energy systems", IEEE Transactions on Power Apparatus and Systems, vol.89, no.4, pp.556-563, April 1970.

[3] NaimulHasan,"An Overview of AGC Strategies in Power SystemInternational Journal of Emerging Technology and Advanced Engineering", vol.2, Issue 8, pp.August 2012.

[4] S.Ganapathy and S.Velusami, "MOEA based Design of Decentralized Load-Frequency Controllers for Interconnected Power Systems with AC-DC Parallel Tielines and Considering Nonlinearities", International Journal of Computer Applications 1(8):32-37, February 2010.

[5] M.Tuba, I.Brajevic and R.Jovanovic, "Hybrid Seeker Optimization Algorithm for Global Optimization",Applied Mathematics \& Information Sciences, vol.7, No. 3, pp.867-875, May 2013.

[6] Saxena, A, Gupta, M, GuptaV, "Automatic generation control of two area interconnected power system using Genetic algorithm", Proceedings of IEEE International Conference on Computational Intelligence \& Computing Research (ICCIC), Coimbatore, India, pp.1-5, 18-20 Dec. 2012.

\section{AUTHOR'SPROFILE}

S.Rameshkumar was born in Chidambaram, India in 1982. $\mathrm{He}$ received Bachelor of Engineering in Electrical and Electronics Engineering and Master of Engineering in Power systems from Annamalai University in 2003 and 2008 respectively. Currently he is an assistant professor in Dept of Electrical Engineering, Annamalai University. He is doing his research work in the area of Power system load frequency control.

S. Ganapathy was born in Chennai, India in 1967. He received Bachelor of Engineering in Electrical and Electronics Engineering, Master of Engineering in Power systems and Ph.D from Annamalai University in 1990, 1995 and 2010 respectively. Currently, he is a professor in the Dept. of Electrical Engineering, Annamalai University. His research interests include power system control and application of computational intelligence to power systems. He has published over 15 papers in leading journals and conferences. $\mathrm{He}$ is a life member of Indian Society for Technical Education. 